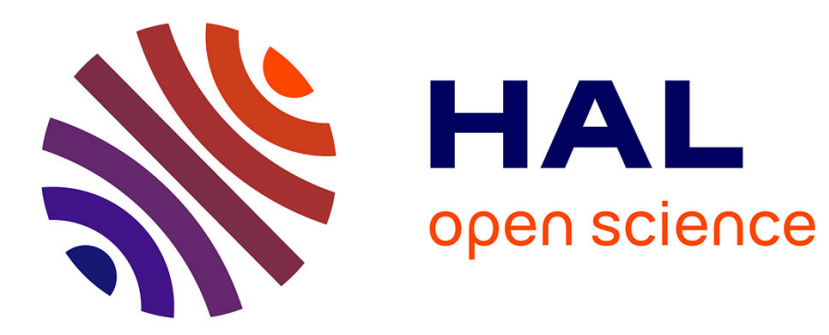

\title{
HIV/AIDS Knowledge and Accessibility to Information Sources Between Blind and sighted Populations in Nigeria
}

\author{
Wim Otte, Frank Maas, Anthonius De Boer
}

\section{- To cite this version:}

Wim Otte, Frank Maas, Anthonius De Boer. HIV/AIDS Knowledge and Accessibility to Information Sources Between Blind and sighted Populations in Nigeria. AIDS Care, 2008, 20 (09), pp.1093-1097. 10.1080/09540120701842787 . hal-00513441

\section{HAL Id: hal-00513441 \\ https://hal.science/hal-00513441}

Submitted on 1 Sep 2010

HAL is a multi-disciplinary open access archive for the deposit and dissemination of scientific research documents, whether they are published or not. The documents may come from teaching and research institutions in France or abroad, or from public or private research centers.
L'archive ouverte pluridisciplinaire HAL, est destinée au dépôt et à la diffusion de documents scientifiques de niveau recherche, publiés ou non, émanant des établissements d'enseignement et de recherche français ou étrangers, des laboratoires publics ou privés. 

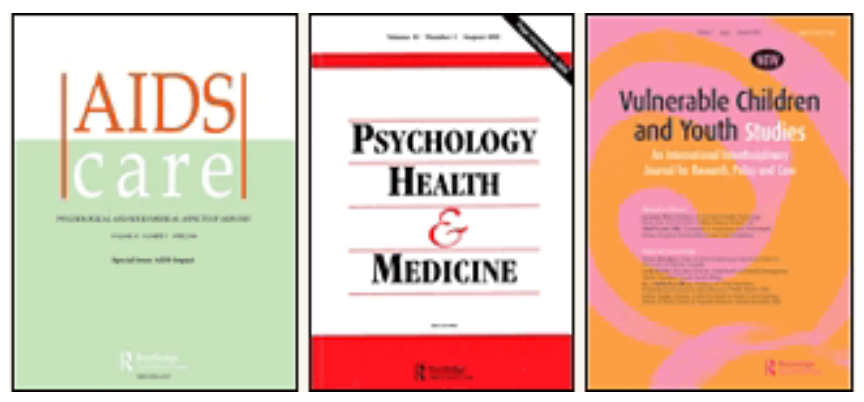

HIV/AIDS Knowledge and Accessibility to Information Sources Between Blind and sighted Populations in Nigeria

\begin{tabular}{|r|l|}
\hline Journal: & $\begin{array}{l}\text { AIDS Care - Psychology, Health \& Medicine - Vulnerable Children } \\
\text { and Youth Studies }\end{array}$ \\
\hline Manuscript ID: & AC-2007-05-0233.R1 \\
\hline Journal Selection: & AIDS Care \\
\hline Keywords: & Blindness, AIDS, HIV, Vulnerable Populations, Nigeria \\
\hline \multicolumn{2}{|}{} \\
\hline
\end{tabular}

\section{scholarONE \\ Manuscript Central}


Comparison of Knowledge and Accessibility to Information Sources of HIVIAIDS Between Blind and Sighted Populations in Nigeria 


\section{Abstract}

The aim of this study was to compare the HIVIAIDS knowledge and accessibility to HIVIAIDS information between blind and sighted individuals in Nigeria. A cross-sectional survey was undertaken among rural and urban blind (57) and sighted (62) adolescents in 2006. A structured questionnaire was used to collect data about HIVIAIDS symptoms, transmission and prevention knowledge, as well as accessibility to sources of HIVIAIDS information. Binary logistic regression and chi-square statistics were applied to compare responses between the two populations. Blindness was found to be associated with diminished knowledge of HIVIAIDS transmission, prevention and symptoms. At the same time blind rely on different sources of HIVIAIDS information than the sighted respondents. A lack of knowledge and limited accessibility to proper sources of information causes the blind disabled to be more vulnerable. It is necessary to supply them with proper information and increase their HIVIAIDS knowledge. 


\section{Introduction}

In the spread of the HIVIAIDS epidemic, the more vulnerable populations are at particularly risk of HIV

contraction. Among them are the visual disabled. Approximately 600 million disabled individuals are

living among the poorest, least educated, and most marginalized people around the world (Groce,

2003). From them the estimates of the WHO state a figure of 161 million visually impaired (about $2.6 \%$ of the world population) in the year 2002 (WHO, 2004). The number of blind and visually impaired individuals throughout the world will continue to rise, mainly because of population growth and the increase in life expectancy. The majority of the visually impaired lives in developing countries which are disproportionate hit by the HIVIAIDS epidemic. Because of the lack of a cure, the focus of controlling this growing disaster is education and prevention. It is clear that disabled people are vulnerable to HIV infection, but most of the time they are not seen as a risk group. Lack of information, access, abuse and extreme poverty leads to increased vulnerability (Nosek, 2001). In Africa, the population of people living with a disability is more than ten percent, but only a few studies are available about the level of HIVIAIDS knowledge among the disabled.

Previous research compared the HIVIAIDS knowledge among deaf and hearing college students in the USA (Heuttel, 2001). Studies done in Swaziland (Yousafzai, 2004; Groce 2006) and Nigeria (Groce, 2007), demonstrated that disabled and deaf are prone to misunderstanding and have less accessibility to information sources. Furthermore, jn a recent study from South Africa the authors advised to perform more studies on the prevention of HIVIAIDS among South Africans with visual impairments (Philander, 2006). \n other African countries no such studies are available, Therefore, we conducted a study among visual impaired and sighted youth in the developing country Nigeria. The study was done in the southeast part of the country where the estimated adult HIV prevalence rate is 6.4 percent (UNAIDS, 2006). No data on the prevalence of HIV infection in any disabled population in Africa are available (Groce, 2003).

The purpose of the study was to compare HIV knowledge and accessibility to HIVIAIDS information sources among blind and sighted adolescents in Nigeria.

\section{Methods}

Data collection

\begin{tabular}{l} 
Deleted: show \\
Deleted: \\
Deleted: A key informant s \\
Deleted: done in \\
Deleted: among fifteen participants \\
investigation is needed in the \\
Deleted: prevention area for \\
Deleted: \\
Deleted: Particularly information \\
from the visual impaired \\
Deleted: i \\
Deleted: \\
Deleted: concerning this \\
differences, is not available, \\
Deleted: despite the higher \\
vulnerability of these individuals. \\
Deleted: For this reason \\
Deleted: the \\
Deleted: a \\
Deleted: of Nigeria \\
Deleted: is \\
\hline
\end{tabular}


A cross-sectional structured survey was performed among 119 adolescents in Jzzi. Jzzi is a rural area, about $1940 \mathrm{~km} 2$, located in the northeastern part of Ebonyi State and partly in the bordering Southern

part of Benue State, in the South East of Nigeria. Because of the relatively large distances between, and bad accessibility to, the many small villages and towns, we choose to restrict our population

sample to school communities. Jzzi contains primary schools for the blind, but lacks secondary schools accessible for visually impaired people. The average age in the highest class of a primary school for the blind is significantly higher compared to an equal class on a regular primary school. For this reason the survey was conducted among the highest classes of three primary schools of the blind $(n=57)$ and lowest classes of three regular secondary schools $(n=62)$. Schools were selected at random from all available Izzi schools (three out of seven primary blind schools and three out of thirtyfive, regular secondary schools). Because this was the first study on HIVIAIDS knowledge performed in Nigeria no sample size calculation could be conducted prior to study start The sample sizes were chosen as large as possible. The questionnaire, containing multiple-choice and open questions, was divided into four main subjects, demography, modes of HIV transmission, modes of HIV prevention

Deleted: 35
Deleted: is
Deleted: adminstered
Deleted: power analysis
Deleted: a priori
Deleted: are
and accessibility to different sources of HIVIAIDS information.

The questions were constructed from two previous HIVIAIDS knowledge studies done in Swaziland (Yousafzai, 2004) and Nigeria (Groce, 2007). The questions were piloted, and then administered by the trained local workers of the non-governmental organization Community Based Rehabilitation Effata. On the six schools sighted (Ndioke, Onenyim Iseke and Obudu secondary school) and blind (Iboko, Guidiri and Obudu primary school) participants were chosen at random from every third person in the classroom. The sighted individuals completed the questionnaire mostly by themselves. The blind received help from a worker. The workers read the questions and wrote the answers when helping the blind people. Only questions for clarification were allowed to be asked.

All schools have given written or oral consent to take part in the study and also the children had to give

Deleted: except for $t$ Deleted: , they

Deleted: must oral consent prior to participation.

\section{Statistical analysis}

- Bjnary logistic regression was used to compare responses and calculate odds ratios from the blind and sighted respondents (Statistical Package for Social Sciences (SPSS) version 15.0). The regression model was also used to adjust, when necessary, for the confounders age, sex, and

Deleted: After entering the results into the Statistical Package for Social Sciences (SPSS) version 15.0

Deleted: b

Deleted: applied

Deleted: relative odd ratio

Deleted: binary logistic regression model were tested 
residence. Per confounder, a change of $>10 \%$ in odds ratio was considered as a criteria to include the concerning confounder in the final model. The AIDS symptoms open-ended question was analyzed by categorizing the mentioned symptoms into the most related answers and tested for significant difference using $\underline{\text { Ch}}$ i-square statistics. Due to extreme diverse answers we did not include the open questions: 'What is the meaning of Window period?'; 'What is the meaning of voluntary counselling and testing (VCT)?'; 'What is the meaning of anti-retroviral (ARV)?'; 'How can HIV be transmitted from mother to child?', and 'What do you think is important for us to know about HIVIAIDS in your community that we have not asked?' in the analysis. The only open question included was: 'What are the symptoms of AIDS?'

\section{Results}

\section{Demography}

Table 1 shows the demographic data from the blind $(n=57)$ and sighted $(n=62)$ groups. Most participants were within the age category $11-20$ years 1 In spite of the lower education level the average age among visually impaired respondents was, higher than in the sighted adolescents.

\section{HIV transmission}

The assumed modes of HIV transmission are presented in Table 2. In general, the wrong ideas about modes of transmission of HIV tended to be higher among the visually impaired than among the sighted individuals. However, this trend was only significant for kissing as a mode of transmission (odds ratio of blind versus sighted individuals was, 2,3 ,

\section{HIV prevention, treatment and symptoms}

Comparing the assumed modes of HIV prevention also resulted in a trend that plind individuals had, greater risk in believing the wrong prevention modes (Table 3). Only two odds ratios were, significant, testing your blood for HIV before transfusion (odds ratio 11, $1 ; \mathrm{p}<0,001$ ) and eating good food (odds ratio 3,$9 ; p<0,001)$. Questions related to HIVIAIDS treatment, including 'Is there is vaccine against HIV', 'Is there a HIV blood test', and 'AIDS patients may look healthy', did not show significant differences between the two groups of respondents. The categorized AIDS symptoms are represented
Deleted: A

Deleted: odd ratio

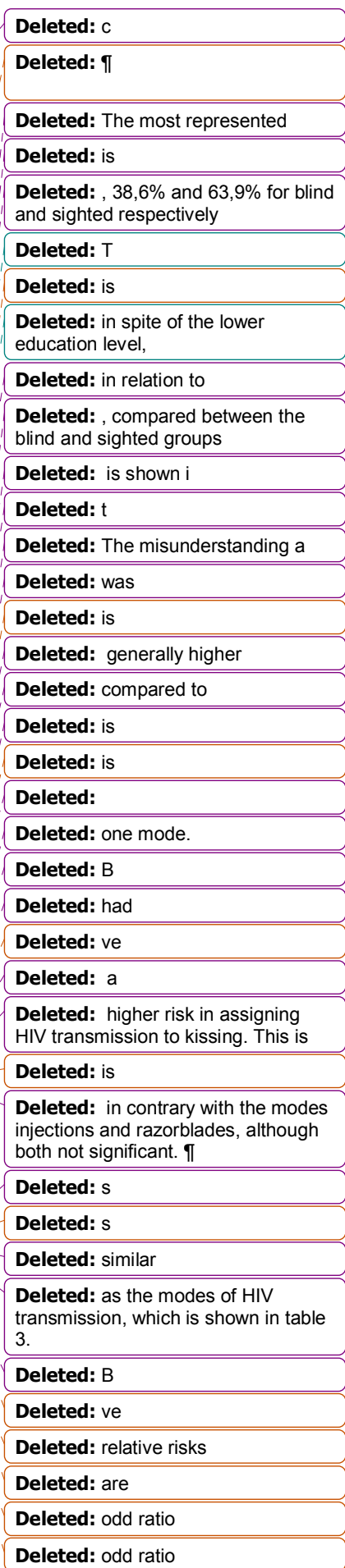


in Table 4. The main categories with significant differences were weight loss, diarrhea, coughing and rashes.

Accessibility to different sources of HIVIAIDS information

Table 5 contains the results of the accessibility to different sources of HIVIAIDS information.

Significant differences were seen in the category posters - billboards, hospital - clinic and church mosque. The remaining questions (not shown in table), 'do you know anybody with HIVIAIDS', 'has Deleted: are Deleted: are anyone come to your school to talk about HIVIAIDS', and 'is there a lesson in the school about HIVIAIDS, had $2,4(p$ 0,05), 0,1 ( $p<0,001)$, and 1,2 (p 0,62) as odds ratio, respectively.

Deleted: ve

\section{Discussion}

This study demonstrated differences in HIVIAIDS knowledge and accessibility to HIVIAIDS information between blind and sighted youth in Nigeria. Blind disabled are more prone to misunderstanding and rely on different sources of information than sighted individuals.

In the limited studies available about HIVIAIDS knowledge in disabled, most of them are restricted to deaf populations. This is the first survey done among blind adolescents. Moreover this study was not done in the western world, but in an African country hit by the HIV epidemic, making the results more relevant for the places where help is needed most.

According to the results of studies done among deaf adolescents in the USA (Heuttel 2001; BatChava, 2005), Swaziland (Yousafzai, 2004; Groce 2006) and Nigeria (Groce, 2007), we found that blind disabled are prone to more misunderstanding and wrong information. The blind disabled think kissing is a mode of HIV transmission (odds ratio 2,3). Also for other transmission modes the blind group tended to have the wrong ideas, We found the blind not to appreciate HIV blood test as a mode of prevention (odds ratio 13,0) and they falsely believe that eating good food is an adequate mode of prevention (odds ratio 3,9 ).

Both groups were able to state the main AIDS related symptoms, however, in all cases the percentage of stated symptoms was, low. We consider these, results to be caused by lower levels of literacy, which

\section{Deleted: s}

Deleted: the existence of

Deleted: the greater part is

Deleted: the

Deleted: of the deaf.

Deleted: research

Deleted: is

Deleted: ,

Deleted: odd ratio

Deleted: The other modes of transmission show a trend of increased believe of the wrong modes among the blind.

Deleted: more often to think that wim dit snap ik niet helemaal: uit table 3 blijkt toch dat blinden 13 maa vaker denken dat HIV-testen van vaker denken dat HIV-testen van
bloed voor transfusie (en ik neem aan dat hier bedoeld is testen van het transfusiebloed) goed is voor de preventie van HIV; en dat is toch goed??]

Deleted: odd ratio

Deleted: odd ratio

Deleted: are

Deleted: i

Deleted: s

Deleted: Weight loss is mentioned 36 times $(39,6 \%)$ in the blind group, but only 6 times in the sighted group. Coughing and diarrhea are believed

to be AIDS related symptoms in only $9,6 \%$ and $1,2 \%$ of the cases in the sighted group, and $1,1 \%$ and $7,7 \%$ in the blind group. $\mid$

Deleted: [het valt hier toch op dat de kennis erg tegenvalt, als je bij v. kijkt naar gewichtsverlies, hoesten etc] although the frequency per symptom differs between the groups.

Deleted: is 
interferes with their ability to understand HIVIAIDS information. Although blind individuals are able to talk and listen they are often isolated from the surrounding society. This could strengthen their

\section{HIVIAIDS misinformation which is often received through stories, folklore and rumors.}

Great difference was, found in the accessibility to different sources of HIVIAIDS information. The result in the poster - billboard source of information category (odds ratio 0,1 ) is not surprising concerning the disability of the visual impaired. The remarkable low information source for hospital - clinic (odds ratio $0,1)$ is similar to the results found in the Swaziland survey by Groce et al The inadequate physical access to clinics and hospital and lack of both confidentiality for people with communication impairments and disability-friendly medical information, as reported by Groce (Groce, 2004), is probably the cause of this finding. However, they found religious organizations as a diminished source of information for deaf, which is in contrast with our findings (odds ratio 5,5 ). The vocal information as the only communication mode in churches and mosques is probably the cause for differences between deaf and blind individuals.

\section{Limitations of our study must be acknowledged. Due to the differences between Northern and}

Southern Nigeria the results are not representative for the country as a whole. Extrapolation of results to other countries might also be questionable, Several trends which were not statistical significant might become slearer with an increased sample size. The restriction of the survey population to school communities will have influenced our results. The poorest families have limited money available for education of their children. Furthermore, the non-disabled family members are most of the time chosen to go to school while the disabled, and especially the blind, are kept at home.

We compared the HIV knowledge together with the accessibility to HIVIAIDS information sources among the blind and sighted. It was shown that not only the deaf but also the blind are a vulnerable population. More research on the knowledge between blind and sighted groups is needed. Because of the great differences between Christian and Muslim states in Nigeria, a national investigation is important.

A lack of knowledge and a limited accessibility to proper sources of information on HIVIAIDS causes an unnecessary vulnerability. Because this is found particularly in individuals with a disability, it is
Deleted: is

Deleted: odd ratio

Deleted: odd ratio

\begin{tabular}{|l|}
\hline Deleted: in \\
\hline Deleted: $n$ \\
\hline Deleted: $\mathrm{i}$ \\
\hline Deleted: and colleges \\
\hline Deleted: et al \\
\hline Deleted: \\
\hline Deleted: source $\mathrm{n}$ \\
\hline Deleted: ry \\
\hline
\end{tabular}

Deleted: is

Deleted: It is not telling much about the situation in other countries either Deleted: The

Deleted: is seen would probably be Deleted: the

Deleted: y

Deleted: results in a distorted picture Deleted: very

Deleted: $T$

Deleted: is s

Deleted: too

Deleted: indeed

Deleted: The differences are clear, however they plead for more 
necessary in HIVIAIDS prevention campaigns to pay specific attention to this group of individuals and supply them with proper information to increase their knowledge.

\section{Acknowledgements}

We thank the staff of the Community Based Rehabilitation program Effata for the data collection.

\section{References}

1. Groce, N.E. (2003). HIVIAIDS and people with disability. The Lancet, 361, 1401-1402

2. World Health Organization (WHO). (2004). Magnitude and causes of visual impairment. Fact Sheet $N^{\circ} 282$, http://www.who.int/mediacentre/factsheets/fs282/en/ [visited 26-02-2006]

3. Heuttel, K.L., et al. (2001). HIVIAIDS knowledge and information sources among deaf and hearing college students. American annals of the deaf, 146, 280-286

4. Nosek, M.A., et al. (2001). The Investigation of Abuse and Women With Disabilities. Violence against women, 7, 477-499

5. Yousafzai, A.K., et al. (2004). Knowledge, personal risk and experiences of HIVIAIDS among people with disabilities in Swaziland. International journal of rehabilitation research, 27, 247-251

6. Groce, N., et al. (2006). HIVIAIDS and disability: a pilot survey of HIVIAIDS knowledge among a deaf population in Swaziland. International journal of rehabilitation research, 29, 319-324

7. Philander, J.H., et al. (2006). Needs, Barriers, and Concerns Regarding HIV Prevention among South Africans with Visual Impairments: A Key Informant Study. Journal of Visual Impairment \& Blindness, 100, 111-114

8. Groce, N.E., et al. (2007). HIVIAIDS and disability: Differences in HIVIAIDS knowledge between deaf and hearing people in Nigeria. Disability and rehabilitation, 29, 367-371

9. Groce, N.E. (2004). Capturing hidden voices. Washington, DC: The World Bank 2004. http://siteresources.worldbank.org/DISABILITY/Resources/Health-and-Wellness/HIVAIDS.pdf [visited 27-09-2007]

10. UNAIDS. (2006). http://www.unaids.org/en/ [visited 26-02-2006]

11. Bat-Chava, Y., et al. (2005). Barriers to HIVIAIDS knowledge and prevention among deaf and hard of hearing people. AIDS Care, 17, 623-634 
Table 1. Demographic data for the participating blind and sighted adolescents $(n=119)$.

\begin{tabular}{|c|c|c|c|c|c|}
\hline & & \multicolumn{2}{|c|}{ Sighted } & \multicolumn{2}{|l|}{ Blind } \\
\hline & & $\mathrm{n}$ & $\%$ & $n$ & $\%$ \\
\hline \multirow[t]{4}{*}{ Age } & $10-15$ years & 14 & 23,0 & 19 & 33,3 \\
\hline & $11-20$ years & 39 & 63,9 & 22 & 38,6 \\
\hline & $21-30$ years & 8 & 13,1 & 15 & 26,3 \\
\hline & $31-40$ years & 0 & 0,0 & 1 & 1,8 \\
\hline \multirow[t]{2}{*}{ Sex } & Male & 46 & 75,4 & 39 & 68,4 \\
\hline & Female & 15 & 24,6 & 18 & 31,6 \\
\hline \multirow[t]{2}{*}{ Married } & Yes & 6 & 9,7 & 3 & 5,3 \\
\hline & No & 56 & 90,3 & 54 & 94,7 \\
\hline \multirow[t]{2}{*}{ Residence } & Urban & 29 & 46,8 & 21 & 36,8 \\
\hline & Rural & 33 & 53,2 & 36 & 63,2 \\
\hline \multirow[t]{5}{*}{ Village } & Iboko & 0 & 0,0 & 20 & 35,1 \\
\hline & Obudu & 21 & 33,9 & 18 & 31,6 \\
\hline & Guidiri & 0 & 0,0 & 19 & 33,3 \\
\hline & Ndioke & 22 & 35,5 & 0 & 0,0 \\
\hline & Onenyim Iseke & 19 & 30,6 & 0 & 0,0 \\
\hline \multirow[t]{2}{*}{ Denomination } & Christian & 61 & 98,4 & 56 & 98,2 \\
\hline & Muslim & 1 & 1,6 & 1 & 1,8 \\
\hline \multirow[t]{2}{*}{ Read/Write } & Yes & 60 & 96,8 & 56 & 98,2 \\
\hline & No & 2 & 3,2 & 1 & 1,8 \\
\hline
\end{tabular}

Table 2. The association of blind versus sighted in believe of mode of HIV transmission.

\begin{tabular}{|c|c|c|c|}
\hline & Number true (\%) sighted & Number true $(\%)$ blind & (Un)adjusted OR (95\% Cl) p-value \\
\hline Through mosquito bites & $14(45.2 \%)$ & $17(54.8 \%)$ & $1,5(0,6-3,3) 0,37$ \\
\hline Through kissing & $12(35.3 \%)$ & $22(64.7 \%)$ & $2,3(1,0-5,3) 0,048$ \\
\hline $\begin{array}{l}\text { Through sexual } \\
\text { intercourse }\end{array}$ & $55(51.9 \%)$ & $51(48.1 \%)$ & $2,1(0,1-9,0) 0,31 \#$ \\
\hline Through sharing spoons & $15(46.9 \%)$ & $17(53.1 \%)$ & $1,2(0,5-2,8) 0,64$ \\
\hline Through touching & $7(50.0 \%)$ & $7(50.0 \%)$ & $1,0(0,3-3,2) 0,95$ \\
\hline Through injections & $50(48.5 \%)$ & $53(51.5 \%)$ & $0,3(0,1-1,2) 0,08 \&$ \\
\hline Through razorblades & $52(49.1 \%)$ & $54(50.9 \%)$ & $0,4(0,1-1,7) 0,22$ \\
\hline $\begin{array}{l}\text { Through pregnancy } \\
\text { (mother - child) }\end{array}$ & $46(53.5 \%)$ & $40(46.5 \%)$ & $1,8(0,8-4,5) 0,18$ \\
\hline Through coughing & $14(43.8 \%)$ & $18(56.3 \%)$ & $1,4(0,6-3,2) 0,41$ \\
\hline
\end{tabular}

Table 3. The association of blind versus sighted in believe of mode of HIV prevention.

\begin{tabular}{|c|c|c|c|}
\hline & Number true (\%) sighted & Number true (\%) blind & (Un)adjusted OR $(95 \% \mathrm{Cl}$ ) p-value \\
\hline Avoid dirty places & $12(40.0 \%)$ & $18(60.0 \%)$ & $1,8(0,8-4,2) 0,17$ \\
\hline $\begin{array}{l}\text { Test blood for HIV before } \\
\text { transfusion }\end{array}$ & $57(58.2 \%)$ & $41(41.8 \%)$ & $13,0(2,7-61,9) 0,001 \$$ \\
\hline Use clean needles & $47(52.2 \%)$ & $43(47.8 \%)$ & $1,7(0,7-4,3) 0,27$ \\
\hline Not sharing spoons & $17(45.9 \%)$ & $20(54.1 \%)$ & $1,3(0,6-2,9) 0,51$ \\
\hline Use condoms & $39(54.2 \%)$ & $33(45.8 \%)$ & $1,3(0,6-2,8) 0,50$ \\
\hline Practice abstinence & $44(48.9 \%)$ & $46(51.1 \%)$ & $1,0(0,4-2,4) 0,93$ \\
\hline Eat good food & $11(28.9 \%)$ & $27(71.1 \%)$ & $3,9(1,7-9,0)<0,001$ \\
\hline
\end{tabular}

\$ Adjusted for age 
Table 4. The symptoms believed to be AIDS related, in blind and sighted adolescents.

\begin{tabular}{|c|c|c|c|c|}
\hline$x^{2}$ & Sigl & & Blir & \\
\hline Symptom & $\mathrm{n}$ & $\%$ & $\mathrm{n}$ & $\%$ \\
\hline Weight Loss * & 6 & 7,2 & 36 & 39,6 \\
\hline Coughing * & 8 & 9,6 & 1 & 1,1 \\
\hline Diarrhea * & 1 & 1,2 & 7 & 7,7 \\
\hline Rashes & 15 & 18,1 & 8 & 8,8 \\
\hline Fever * & 1 & 1,2 & 3 & 3,3 \\
\hline Open wounds/sores * & 5 & 6,0 & 2 & 2,2 \\
\hline Headache & 2 & 2,4 & 3 & 3,3 \\
\hline Frequently ill & 5 & 6,0 & 10 & 11,0 \\
\hline Weakness & 3 & 3,6 & 4 & 4,4 \\
\hline Vomiting & 1 & 1,2 & 3 & 3,3 \\
\hline Emaciation & 3 & 3,6 & 0 & 0,0 \\
\hline Poor hair growth & 3 & 3,6 & 0 & 0,0 \\
\hline Skin problems & 3 & 3,6 & 6 & 6,6 \\
\hline Others * & 11 & 13,3 & 2 & 2,2 \\
\hline No answer * & 16 & 19,3 & 6 & 6,6 \\
\hline
\end{tabular}

* Significant categories $(p<0.05)$

\begin{tabular}{|c|c|c|c|}
\hline & Number true (\%) sighted & Number true (\%) blind & (Un)adjusted OR (95\% Cl) p-value \\
\hline Television & $36(58.1 \%)$ & $26(41.9 \%)$ & $0,6(0,3-1,3) 0,18$ \\
\hline Radio & $50(49.5 \%)$ & $51(50.5 \%)$ & $2,7(0,9-8,4) 0,09 \#$ \\
\hline Posters or Billboards & $31(91.2 \%)$ & $3(8.8 \%)$ & $0,1(0,0-0,2)<0,001$ \\
\hline School & $40(58.0 \%)$ & $29(42.0 \%)$ & $0,6(0,3-1,2) 0,13$ \\
\hline Parents & $32(58.2 \%)$ & $23(41.8 \%)$ & $\underline{0,6(0,3-1,3) 0,22}$ \\
\hline Friends & $31(50.8 \%)$ & $30(49.2 \%)$ & $1,1(0,5-2,3) 0,77$ \\
\hline Hospital or Clinic & $44(80.0 \%)$ & $11(20.0 \%)$ & 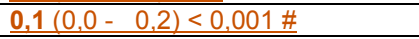 \\
\hline Church or Mosque & $28(38.9 \%)$ & $44(61.1 \%)$ & 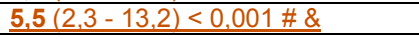 \\
\hline Village Meetings & $20(58.8 \%)$ & $14(41.2 \%)$ & $0, \mathbf{7}(0,3-1,5) 0,35$ \\
\hline Others & $16(94.1 \%)$ & $1(5.9 \%)$ & $\underline{0,5}(0,1-0,3) 0,01$ \\
\hline
\end{tabular}

\# Adjusted for sex

\& Adjusted for residence 
$\underline{\text { Response to referee comments re. manuscript AC-2007-05-0233 }}$

We would like to thank the referees for their critical evaluation of our manuscript. Our response to their comments is given below.

\section{Referee \#1}

Major comments:

1. Methods: data collection

a) How was the sample size determined to estimate the number of blind and normal sighted persons required for this study?

We had no information on response rates (and confidence intervals) of the questions of our survey in the Nigerian population. Therefore we did not perform a formal sample size calculation but we based our numbers of participants on logistic considerations. One school could be done in one day. Given one day in the week the local workers were available, resulted in six schools per six weeks (time available to collect data). To explain our sample size considerations we added additional text to the 'Data collection' part in the method section.

b) How were schools selected/ sampled? Three schools were selected in each group, out of how many?

Schools were selected at random from all available schools. Available schools were seven primary blind schools and thirty-five secondary schools. (Added to section Methods).

c) Questionnaires: What was the language of administering the questionnaire? Was there translation involved?

The official language in the Nigerian educational system is English. For this reason the questionnaire was administered in English too. There was no translation involved.

\section{Methods: statistical analysis}

The authors describe the criteria for inclusion of confounders in the adjusted regression model as a change of $10 \%$ odds ratio.

I suggest that the authors should analyze the data again and use the log-likelihood ratio test with a $5 \%$ level of significance (i.e. p-value $<0.05$ ) to determine if a confounding variable should be included in the adjusted model or not. This is a more 
robust statistical approach of determining importance on a variable in a regression model.

We do not want to follow the suggestion of the referee to include potential confounders in the regression model based on significance. This approach should be used when the purpose of the analysis is to construct a prediction model (for instance like the Framingham risk function). In that case you could also use forward and backward selection. When a prediction model is build one does not give odds ratios but receiver operating characteristic (ROC)-curves, sensitivity, specificity, positive predicting value, etc. In this study we wanted to estimate odds ratios for blinded versus sighted school children. When necessary these odds ratios should be adjusted for potential confounders. Judgement whether a potential confounder should be added to the model should be based on the change of the estimation of the odds ratio of interest and not on a statistical significant contribution to the regression model (method of Sander Greenland)..

\section{Results}

It would be useful to include in table 2 in the unadjusted column the odds ratios and $95 \% \mathrm{Cl}$ for the confounding variable age, sex, and residence. School is also a potential confounder and should be tested as well. These do not have to be repeated in

subsequent tables. The effect estimates (odds ratios) of these confounders are important in interpreting the adjusted results.

We do not agree with this approach, for it is most unusual. Certainly it is possible to present odds ratios of the variables 'age', 'sex', and 'residence', but this is not the study aim. These variables (potential confounders) are only used to estimate the risk of sight versus blind as accurate as possible. We did however include the absolute frequencies in the tables 2,3 , and 5.

Het is een overweging nu ik de tabellen opnieuw zie het volgende te doen:

\section{Discussion}

The authors need to add in the discussion on the limitations of this study.

a) These analyses involve multiple hypothesis testing; therefore some of the associations will be statistically significant as a result of chance. 


\begin{abstract}
Although we realize that when a questionnaire is statistically analyzed that several regression models are constructed it is not customary to perform corrections (like Bonferroni) for multiple testing. The $95 \%$ confidence interval provides enough information on the precision of our study results.
\end{abstract}

b) What is the generalizability of these data generalisable to the Nigerian population? Northern and Southern Nigeria differ in religion, life style and culture. Therefore, our study results cannot be extrapolated to the Northern part of Nigeria. We mentioned this in the Discussion, paragraph 2.

\title{
Minor comments
}

1. Introduction: it would be useful for the authors to provide HIV prevalence estimates among the two study groups: blind and normal sighted.

We do agree with the referee that this would be useful. However, no HIV prevalence data in the literature are available among the subgroups we have studied in Nigeria. We added this lack of prevalence information in the Introduction. The general prevalence for southeast Nigeria is given in the Introduction, paragraph 2, line 7.

\section{Page 4, paragraph 2, line 2:}

Delete the word "relative"

3. Page 5, paragraph 2, line 4:

Change risks to odds

4. Page 5, paragraph 3, line 3:

Change relative risk to odds ratios

Changes are applied.

\section{Other minor comments}

Tense requires correction: e.g. "is" should be changed to "was"; "have" to "had" Tense in Results is changed to past tense. We thank the reviewer for this comment. 


\section{Referee \#2}

\section{General comments:}

The authors are tackling an important subject and the size of the survey group makes this a potentially important contribution to the literature.

A good deal of rewriting and greater discussion is in order. Rather than cite places where re-writing/ re-wording is needed - I would recommend that the editor have the authors go over the paper in-depth with a someone - a colleague or friend - who may have more experience with written English, as there are many places where the points the authors seek to make are obscured by the wording. And since what they are saying is potentially very important, the clearer the writing is, the better.

We thank the reviewer for his/her valuable comments regarding written English. A friend gave recommendations after reading the revised manuscript.

Introduction - An additional citation that the authors should include is Leslie Swartz's recent (last year I believe) paper on blindness and HIV/AIDS in South Africa. Unfortunately, I don't have the citation with me here, but I'm sure a quick literature search should be able to locate it.

As suggested by the referee, we have added this study, done by Philander and Swartz (2006) to the introduction.

Methodology section - the authors note that sighted individuals completed the questionnaire on their own, but blind people received help from a worker. As most of the people questioned were blind presumably, a line or two more about how the worker was able to ensure full cooperation/ confidentiality - would be helpful.

The worker read the questions and wrote the answers when helping the blind people. Only questions for clarification were allowed. This is added to the Method section.

Statistical analysis - Minor point which is implied but not stated - how did the authors link the open-ended question results into the larger survey when they analyzed the data. Due to extreme diverse answers we did not include the open questions: What is the meaning of "Window period"?, What is the meaning of VCT?, What is the meaning of ARV?, How can HIV be transmitted from mother to child?, What do you think is important for us to know about HIV/AIDS in your community that we have not asked? in the analysis. The only open question included was: "What are the symptoms of AIDS?" [Table 4]. We have added this open-question exclusion to the Method section.

The text states that A logistic regression analysis is performed to determine whether age, sex, and residence confound the association with sightedness and various outcome variables. However, the authors never show that age, sex, or residence are associated with the outcome variables in univariate analysis; furthermore, the adjustment is made only for some of the variables and not all. For example, in Table 2 the variable sexual intercourse is adjusted for sex (but not residence or age) and the variable "through injections" is adjusted for residence (and not sex or age). Tables 3 and 5 have similar problems.

The referee likes us to show that our potential confounders are associated with our outcomes. We think this is not needed. The potential confounders we evaluated were the ones which are always used as confounding variables (age and sex) and residence which is also on a theoretical basis likely to be associated with the answers on the questions of our survey. For evaluation of confounding it is not necessary to show that the individual confounders are 
associated with the outcome it is sufficient to evaluate whether they confound our odds ratios. .Another reason not to present the quantitative associations between the potential confounders and the question outcomes is that the number of tables and the data presented in the tables is already high.

Univariate analysis alone may be more appropriate since the number of people in each group is small. The authors could shorten this paper by noting the outcome variables they tested in the text and using only 1 or 2 short tables to show significant findings.

Although this is a possibility we think that the manuscript will become less informative and arranged. When the referee insists we are willing to change the tables.

HIV Transmission - This is one of several places where the authors should let the reader know that they will return to their findings in the Discussion section - (and then actually come back and discuss their findings). They note that blind people are more likely to assign transmission to kissing. Why is this so - discussion among blind people themselves? Limited avenues for communicating about AIDS for people who are blind? An interesting finding - I'd like to hear the authors discuss why they think this is so. HIV Prevention, treatment and symptoms - As noted above, authors find some interesting patterns - but they do not discuss this in the Discussion section.

Paragraph 3 of the Discussion is enlarged. We think misinformation among blind individuals to be the source of the differences with the non-disabled group. Similarities with deaf people are present, however we did not investigate the "why" of the found differences.

Discussion section: The authors do a good job reviewing the statistical findings in the discussion section, but I for one, would very much like to have them spend a paragraph or two talking about WHY they think some of the patterns they have found exist. They can posit these as researchable 'next questions' - but they have done a good job bringing together a relatively sample size, asking a number of good questions and they also seem to have additional experience working with the blind populations. They are too modest about what they know and what they can say.

For example, they state: "Blind disabled ... rely on different sources of information than sighted." Fair enough - tell us a bit what this entails for a blind person in Nigeria in relation to AIDS.

We think that poor access to doctors combined with lacking confidentiality plays an important role. Medical information for blind individuals is lacking altogether. We extended paragraph 4 of the Discussion.

In the next paragraph, they go on to discussion limitations - but again, a few more paragraphs discussing the implications of their findings in greater detail before listing limitations would be good. They call for a need to do a broader survey (different parts of Nigeria will differ because of religious/ethnic differences) - this is important, but nonetheless, these authors have collected a good sized sample and their call for further research shouldn't downplay the findings they are able to present here.

We moved the limitations of the study to the end of the Discussion section.

Minor but important point - Para 2 in Discussion - they refer to 'healthy family members' - someone who is blind is not necessarily 'unhealthy' - what they mean is 'non-disabled.' You can be both disabled AND healthy.

We fully agree with the reviewer and replaced 'healthy' with 'non-disabled'. 